\title{
Italian defeatism unwarranted
}

Sir - Recent public declarations by the Nobel prizewinner Renato Dulbecco have cast a dark shadow over Italian science. In radio and television interviews he has lamented that the Human Genome Project is not getting funds, that the project is dead and that he may return to the United States.

Funding for the Italian share of the project has so far come from the "progetto finalizzato" of the National Research Council (CNR). Because of a major restructuring of the entire institution (whose budget is more than L1,000 billion (US\$560 million) a year) some 'side projects' have no doubt been neglected, including the Human Genome Project (which receives about $\mathrm{L} 2$ billion a year). Dulbecco was complaining about funding for this project but the message has been perceived and amplified by the media as a major failure for all Italian science.

I am well aware of the existence of serious problems with science policy in Italy, as I unfortunately happen to be directly involved in one of them, but I also know that measures are being taken to improve the situation (see Nature 392, 531; 1998).

Dulbecco's advice (to leave the country) to me directly, and implicitly through his speech to the research community, is defeatist and will not help the younger generation of good, honest scientists who are trying to supplant a system still largely dominated by barons. Nor will it help agencies (such as Telethon and AIRC) that have finally introduced a serious system of research funding, based on scientific peer review, and not on declarations through the media. Serious scientists should work for better management of science in Italy in general, not just worry when their own slice is threatened.

Those who know that the situation is different from that depicted by Dulbecco should make their voices heard and show that there is a way to change the system. Just leaving may be an option for some, but is certainly not the solution for Italian science. Monica Zoppè

Istituto Tecnologie Biomediche

Avanzate CNR of Italy, LITA,

Via Fratelli Cervi 93,

20090 Segrate (MI), Italy

e-mail:zoppe@itba.mi.cnr.it

\section{Funding needed for}

\section{creative science}

Sir - For science to contribute to breakthroughs to help people to live longer and healthier lives, it has to be creative. Pioneers are being squeezed out.

Too many scientists spend their careers repeating what their colleagues and/or competitors do in their field of research, with no new ideas, no new concepts, no creation. The race for grants and rapid publication, if possible in leading scientific journals with a high impact factor, probably account for this behaviour.

Awards like the Realizing Our Potential Awards (ROPA), recently extended in the United Kingdom (Nature 392, 10; 1998), should be developed by governments elsewhere. By allowing the funding of 'risky' projects, they provide scientists with the opportunity to do creative research. Please, let us have more creativity, and more ROPA-like awards, for science in the future.

\section{Bertrand Le Douarin}

Université de Rennes 1,

Faculté de médecine CNRS UPR41,

2, avenue du Professeur Léon Bernard, 35043 Rennes Cedex, France

e-mail:bertrand@upr41.univ-rennes1.fr

\section{New concepts of publication}

Sir — I read with interest your leading article ${ }^{1}$ about the withholding of data from "full and open access", which is increasingly at issue across the sciences.

During the past four years or so, my colleagues and I have been developing methods and procedures for the publication of research data in general and ecological data in particular. Our initial motivation came from the work of the Ecological Society of America's FLED (Future-of-Longterm Ecological Data) Committee $^{3}$ and more recently as part of a National Science Foundation grant supporting the development of a Webbased data management system for ecological analysis and synthesis ${ }^{4}$. This work continues to involve the society (publisher of Ecology) at the editorial, committee and research collaboration levels because of the unique and influential role professional societies and journals play in the debate about intellectual property rights in data.

There are recurring and fundamental issues limiting 'full and open access' to data that are intrinsic to institutionalized scientific research. Examples include the fear of being 'scooped' by someone using one's data or inadequate attribution for one's intellectual investment in a research programme resulting in the data, and the relationship this has to academic career advancement. The efforts of Nature and Science to address the issue of restricted access to data is a crucial and significant crack in the cultural mind-set that fosters, permits and even necessitates the withholding of research data.

The next steps along this path require fuller discussion and involvement of the scientific community along with the funding agencies and academic policymakers. New ideas are needed. As digital library and data repository technology improves and the potential for broader and more rapid dissemination of data increases, consideration needs to be given to new concepts of publication. One approach would be to raise data collections to the status of citeable entities in journals. Academic merit could then be obtained for the development and maintenance of data collections and it would be easier to recognize costs for data maintenance in grant proposals. Without such changes, there will continue to be little incentive for individual scientists to ensure the longterm quality and integrity of their often priceless data.

John Helly

San Diego Supercomputer Center,

University of California, San Diego,

La Jolla, California 92093, USA

e-mail: hellyj@sdsc.edu

1. Nature 391, 617 (1998).

2. National Research Council. Bits of Power: Issues in Global Access to Scientific Data (National Academy Press, Washington DC, 1997).

3. Gross, K. et al. Report of the Committee on the Future of Longterm Ecological Data (1995) http://esa.sdsc.edu/FLED/FLED.html

4. Helly, J., Elvins, T., Sutton, D., Martinez, D. Controlled Publication of Digital Scientific Data: An Example in Ecology. In preparation.

\section{Out of order}

Sir - Blaxter et al. in "A molecular evolutionary framework for the phylum Nematoda" (Nature 392, 71; 1998) incorrectly attribute to me "the view that vertebrate parasites evolved from arthropod parasitic ancestors". The oxyurids of vertebrates have long been considered to have been derived from oxyurids in insects, but to extend this idea to the other orders of the nematode of vertebrates is weird indeed and cannot be attributed to me or to any expert on helminthology I can think of.

Roy C. Anderson

Department of Zoology,

University of Guelph,

Guelph, Ontario,

Canada N1G 2W1 